\title{
Thymoma appearing 9 years after the resection of squamous cell carcinoma of the lip: A case report of triple primary tumors and literature review
}

\author{
NOBUYUKI MARUYAMA ${ }^{1}$, TAKANOBU SASAKI ${ }^{2,3}$, AKIRA ARASAKI $^{1,4}$, \\ AKIKO MATSUZAKI ${ }^{5}$, TOSHIYUKI NAKASONE ${ }^{4}$, TAKAO TERUYA ${ }^{2}$, \\ AKIRA MATAYOSHI ${ }^{4}$, TESSHO MARUYAMA ${ }^{4,6}$, KENNOSUKE KARUBE $^{7}$, JIRO FUJITA $^{8}$, \\ NAOKI YOSHIMI ${ }^{5,9}$, YUKIO KUNIYOSHI ${ }^{10}$ and KAZUHIDE NISHIHARA ${ }^{1,4}$
}

\begin{abstract}
${ }^{1}$ Department of Oral and Maxillofacial Functional Rehabilitation, Graduate School of Medicine, University of the Ryukyus;
${ }^{2}$ Department of Thoracic and Cardiovascular Surgery, University Hospital of The Ryukyus, Nishihara, Okinawa 903-0215;

${ }^{3}$ Department of Thoracic Surgery, Tohoku Medical and Pharmaceutical University Hospital, Sendai, Miyagi 983-8512; Departments of ${ }^{4}$ Oral and Maxillofacial Surgery, and ${ }^{5}$ Pathology, University Hospital of the Ryukyus, Nishihara, Okinawa 903-0215; ${ }^{6}$ Molecular Microbiology Group, Tropical Biosphere Research Center, University of the Ryukyus, Nishihara, Okinawa 903-0213; ${ }^{7}$ Department of Pathology and Cell Biology, Graduate School of Medicine, University of the Ryukyus, Nishihara, Okinawa 903-0215; ${ }^{8}$ Department of Infectious Diseases, Respiratory, and Digestive Medicine (The First Department of Internal Medicine), University Hospital of the Ryukyus; Departments of ${ }^{9}$ Pathology and Oncology, and ${ }^{10}$ Thoracic and Cardiovascular Surgery, Graduate School of Medicine, University of the Ryukyus, Nishihara, Okinawa 903-0215, Japan
\end{abstract}

Received November 18, 2018; Accepted April 9, 2019

DOI: $10.3892 / 01.2019 .10675$

\begin{abstract}
The occurrence of second primary tumor (SPT) following malignancy treatment is common. In patients with head and neck $(H \& N)$ cancer, SPTs principally occur in the $\mathrm{H} \& \mathrm{~N}$ region, lungs or esophagus. Therefore, patient follow-up after cancer treatment is important in order to detect recurrence, metastasis and new primary tumors. However, no standard guidelines on lifelong follow-up imaging are available. Herein, we report a patient who presented with three metachronous primary tumors-squamous cell carcinoma (SCC) of the tongue, SCC of the lip and type A thymoma. The third tumor was incidentally detected during follow-up using contrast-enhanced computed tomography (CT) 9 years following resection of the second tumor. To the best of our knowledge, this specific combination of metachronous tumors has not yet been reported. Based on the literature review, we
\end{abstract}

Correspondence to: Dr Tessho Maruyama, Department of Oral and Maxillofacial Surgery, University Hospital of the Ryukyus, 207 Uehara, Nishihara, Okinawa 903-0215, Japan

E-mail: tesshou.730@gmail.com

Abbreviations: CT, computed tomography; FDG-PET, 2-[ $\left.{ }^{18} \mathrm{~F}\right]-$ fluoro-2-deoxy-D-glucose positron emission tomography; $\mathrm{H} \& \mathrm{~N}$, head and neck; MG, myasthenia gravis; SCC, squamous cell carcinoma; SEER, the Surveillance Epidemiology End Results; SPT, second primary tumor

Key words: thymoma, squamous cell carcinoma, oral cavity, lip, cancer, second primary cancer, computed tomography, follow-up observed that thymoma occurs following H\&N cancer treatment. Therefore, to ensure that the presence of subsequent thymomas is not overlooked, we suggest regular lifelong follow-up using contrast-enhanced CT in patients who had previously been diagnosed with $\mathrm{H} \& \mathrm{~N}$ cancer. The literature review revealed that thymomas occur in patients with $H \& N$ cancer and should be detected at the earliest convenience.

\section{Introduction}

Second primary tumors (SPTs) are a common occurrence in daily cancer practice and are a major cause of mortality (1). In patients with head and neck $(\mathrm{H} \& \mathrm{~N})$ squamous cell carcinoma (SCC), SPTs are frequently detected in the $\mathrm{H} \& \mathrm{~N}$ region, lungs, or esophagus years after treatment (2). Therefore, long-term follow-up is critical to detect SPTs as well as recurrence and metastasis $(3,4)$. However, there are no broadly accepted guidelines for lifelong follow-up using computed tomography (CT) (5). Here, we report the case of a patient with metachronous SCC of the tongue, SCC of the lip, and type A thymoma. Thymoma was incidentally detected during follow-up using contrast-enhanced CT 9 years after the second tumor resection. Following the detection, we performed further examinations to clinically diagnose the mass and made preparations to treat the mass; however, the patient initially refused the treatment for the thymoma.

\section{Case report}

In October 2005, a 66-year-old male patient was admitted to our hospital with a 6-month history of pain and ulcer involving 
the left side of the lower lip. The disease was initially diagnosed from biopsy as SCC and treated with cryotherapy (liquid nitrogen) and chemotherapy (local injection of oil bleomycin) at another clinic 2.5 years before the presentation (April 2003). Although the lip mass temporarily disappeared following cryotherapy and chemotherapy, it recurred and pain gradually worsened. Physical examination revealed a hard, elastic $1.3 \times 1.0-\mathrm{cm}$ mass with an ulcer of the left lower lip. No other lesions were observed on the lip or oral cavity, and no palpable neck lymphadenopathy was detected. The patient was a former moderate smoker and former moderate drinker, and his medical history included tongue SCC resection on the right edge of the tongue followed by radical neck dissection on the right side and adjuvant radiotherapy of the neck at another hospital at the age of 33 years (in February 1973). Moreover, the patient had an adenomatous goiter on presentation; however, he has remained stable till date. Regarding family history, his mother had colon cancer and younger brother had esophageal cancer. Contrast-enhanced CTs of the H\&N and chest revealed the enhanced mass in the left lower lip, but no lesions of the tongue, cervical lymph nodes, lungs, mediastinum, or bone were revealed. Similarly, ultrasound and magnetic resonance imaging revealed no neck lesions, and upper gastrointestinal examination revealed no tumorous lesions. The biopsy of the lip confirmed SCC recurrence (Fig. 1). Based on radiographic and clinical assessments, SCC of the lip was graded as RT1NOM0, stage I, according to the Union for International Cancer Control TNM classification (6). The patient underwent local excision of the lip tumor after receiving neoadjuvant chemotherapy with bleomycin (a total dose of $105 \mathrm{mg}$ for approximately 1 month) plus $450 \mathrm{mg}$ uracil/tegafur per day (approximately 1 month), as previously described $(7,8)$. Histopathological examination of the resected tumor further confirmed SCC. No adjuvant therapy was performed.

The patient remained disease-free for 9 years following the treatment for SCC of the lip. During this period, he visited our outpatient clinic regularly for clinical examinations. However, CT had not been performed for 7 years (from 2 years after lip resection) because his clinical lesions were stable. We recommended the patient to perform the CT to detect hidden SPTs or SCC metastasis. Contrast-enhanced CTs of the H\&N and chest (in August 2015) revealed no $\mathrm{H} \& \mathrm{~N}$ lesion but a mass lesion in the mediastinum (Fig. 2A). At the time, no clinical symptoms were found. Subsequent 2-[ $\left.{ }^{18} \mathrm{~F}\right]$-fluoro-2-deoxy-D-glucose positron emission tomography (FDG-PET)/CT revealed high FDG uptake by the mediastinal mass (standardized uptake value max=4.45) (Fig. 2B). Thereafter, gastroendoscopy was performed to examine the gastroesophageal lesion related to the mediastinum mass; however, no lesion was found. Preliminary clinical and radiological diagnosis was mediastinal lymph node metastasis of lip or tongue cancer or metachronous SPT. However, contrary to our advice, the patient initially rejected any further examination or treatment of the mass owing to stress experienced by him because of numerous examinations conducted. However, after 6-month observation period, follow-up using CT revealed mass growth (Fig. 2C). Following an explanation by the thoracic surgeon, the patient finally agreed to treatment (in February 2016). To definitively diagnose the mediastinal lesion, subsequent excision biopsy with video-assisted thoracic surgery was performed, and histological examination revealed thymoma

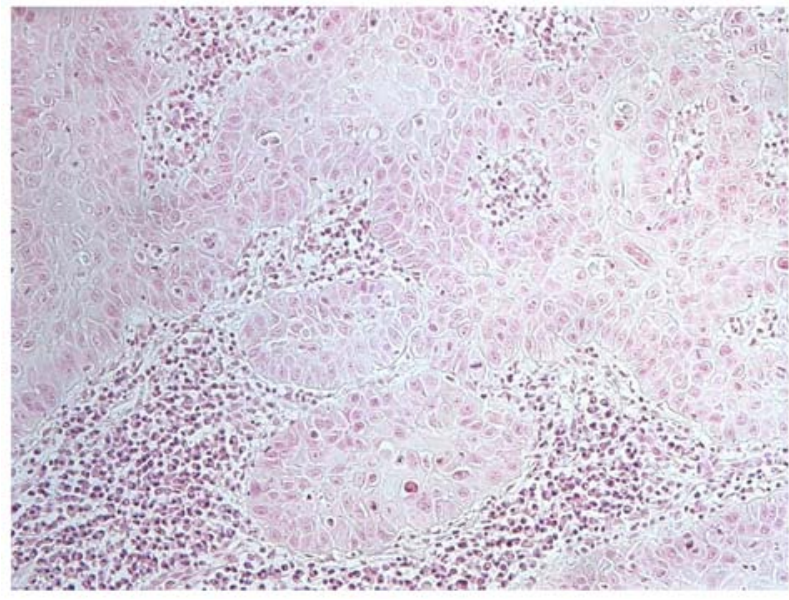

Figure 1. Histological examination by biopsy of the lip tissue by hematoxylin and eosin staining showed squamous cell carcinoma. Magnification, x400.

[World Health Organisation (WHO) classification: Type A; Masaoka stage I] (Fig. 3). In the resected mass, the adhesive proliferation of spindle cells that interspersed with lymphocytes was found in hematoxylin and eosin staining (Fig. 3A). Immunohistochemically, the spindle cells were positive for CK5/6 (Fig. 3B), whereas they were negative for AE1/AE3, CD5, and p16 (data not shown). The lymphocytes was mostly positive for CD3 (Fig. 3C) and CD1a (data not shown) and partly positive for TdT (Fig. 3D). Approximately 10-20\% of the tumor cells were positive for MIB-1 on the lymphocytes (which were also positive for MIB-1) (data not shown). No oral cancer metastasis was histologically found. The study patient was subsequently diagnosed with metachronous triple primary tumors $(9,10)$. After a follow-up period of 2.5 years, the patient is alive and well with no evidence of tumor recurrence, metastatic disease, or any more SPTs.

Written informed consent was obtained from the patient for publication of this case report and the accompanying images. The Ethics Committee of the University of the Ryukyus waived the requirement for review per institutional protocol, as the study does not contain content that requires ethical approval, and approved the submission and publication of this case report.

\section{Discussion}

There are three notable aspects of this case. First, to the best of our knowledge, the specific combination of tumors (SCC of the tongue, SCC of the lip, and type A thymoma) has not been reported previously. Second, we incidentally detected the asymptomatic thymus tumor using CT after an unusually long ( 9 year and 9 months) asymptomatic period following the treatment for the lip SCC. Third, the patient initially refused any further examination or treatment of the new SPT, we believe that patient background is an important prognostic factor for SPT treatment. Through this case, in addition to presenting the case report, we decided to perform an adequate literature review to identify novel cases based on the three aspects of the present case.

To identify previous cases of thymoma with SPT, we performed a literature search for cases with the combined occurrence of $\mathrm{H} \& \mathrm{~N}$ cancer and thymoma (including WHO type $\mathrm{C}$, 

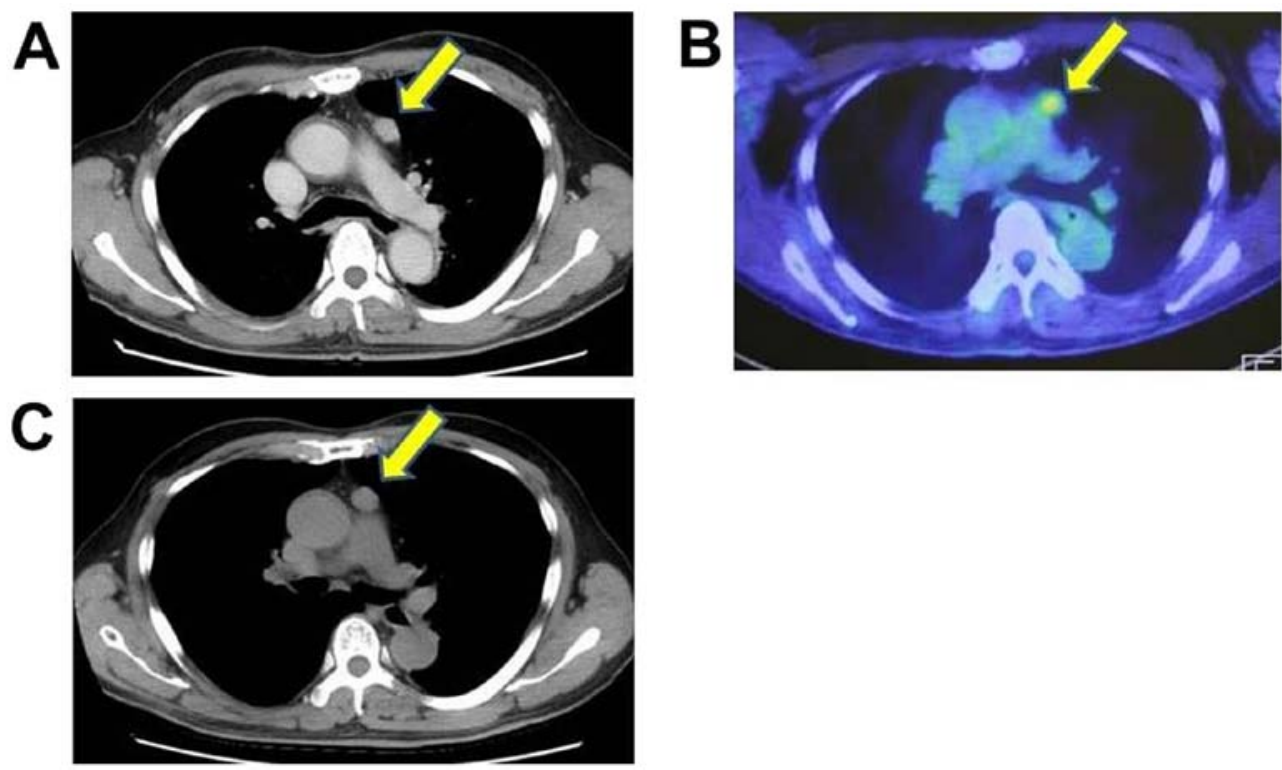

Figure 2. (A) CT scans performed during follow-up after lip surgery for SCC revealed a mass lesion in the mediastinum (arrow) 9 years after SCC diagnosis. (B) Subsequent FDG positron emission tomography/CT showed high FDG uptake by the mediastinal mass (standardized uptake value max=4.45: arrow). (C) A second CT performed 6 months later revealed mass growth (arrow). CT, computed tomography. SCC, squamous cell carcinoma. FDG, 2- $\left.{ }^{18} \mathrm{~F}\right]-$ fluoro-2 -deoxy-D-glucose.

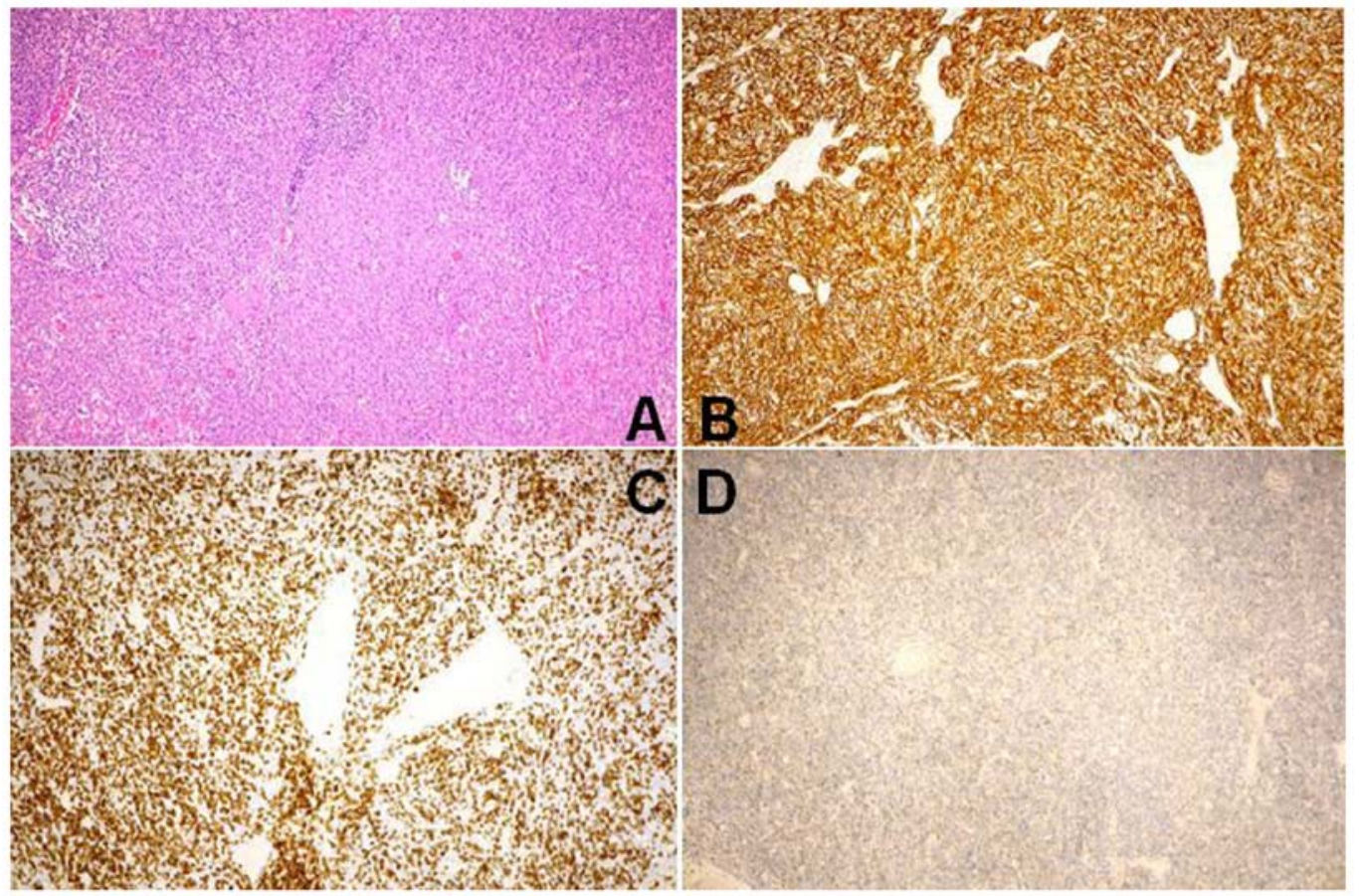

Figure 3. Histological examination of the mediastinal tissue. Subsequent excision biopsy performed using video-assisted thoracic surgery confirmed type A thymoma. (A) In the resected mass, the adhesive proliferation of spindle cells that interspersed with lymphocytes was found. Hematoxylin and eosin staining (magnification, x100). (B) Immunohistochemically, the spindle cells were positive for CK5/6 (magnification, x100). (C) The lymphocytes was mostly positive for CD3 (magnification, x100). (D) The lymphocytes were partly positive for TdT (magnification, x100).

i.e., thymic carcinoma) reported in English using PubMed (https://www.ncbi.nlm.nih.gov/pubmed/) and Google Scholar (https://scholar.google.co.jp/) between 1832 (11) (when thymus was initially reported) and 2018; we excluded non-English literature or conference proceedings, with no other exclusion criteria (Table I) (12-41). Although we identified several cases of thymoma with SPT, we found no case matching the current case of SCC of the tongue, SCC of the lip, and thymoma in sequence.

The present case of thymoma was detected at the small size stage, which may have contributed to successful outcome. There are three major advantages of early thymoma detection. i) Prognosis is worsened by size and invasion (42-45); moreover, progression increases the risk of SPT (36). Unfortunately, 


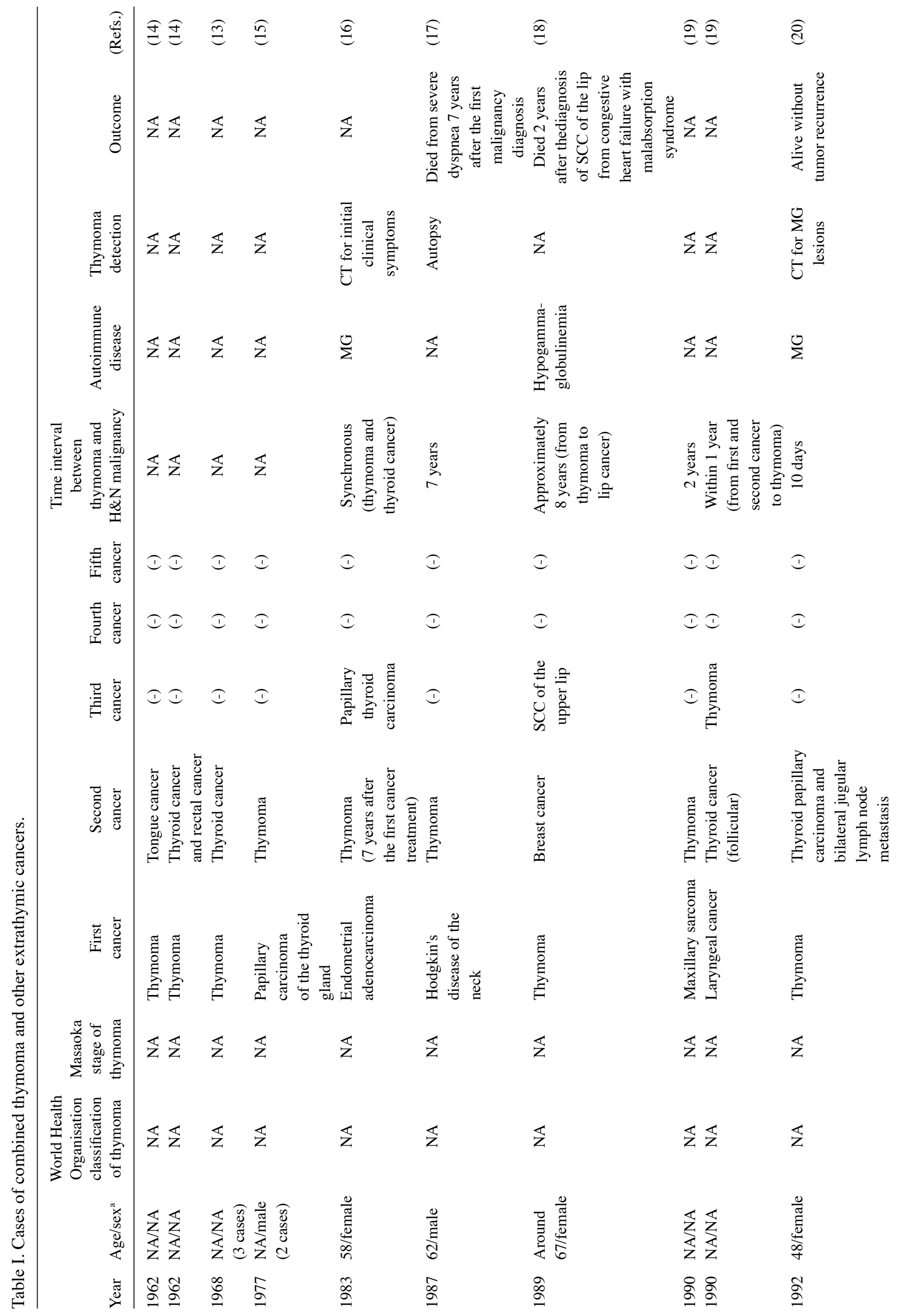




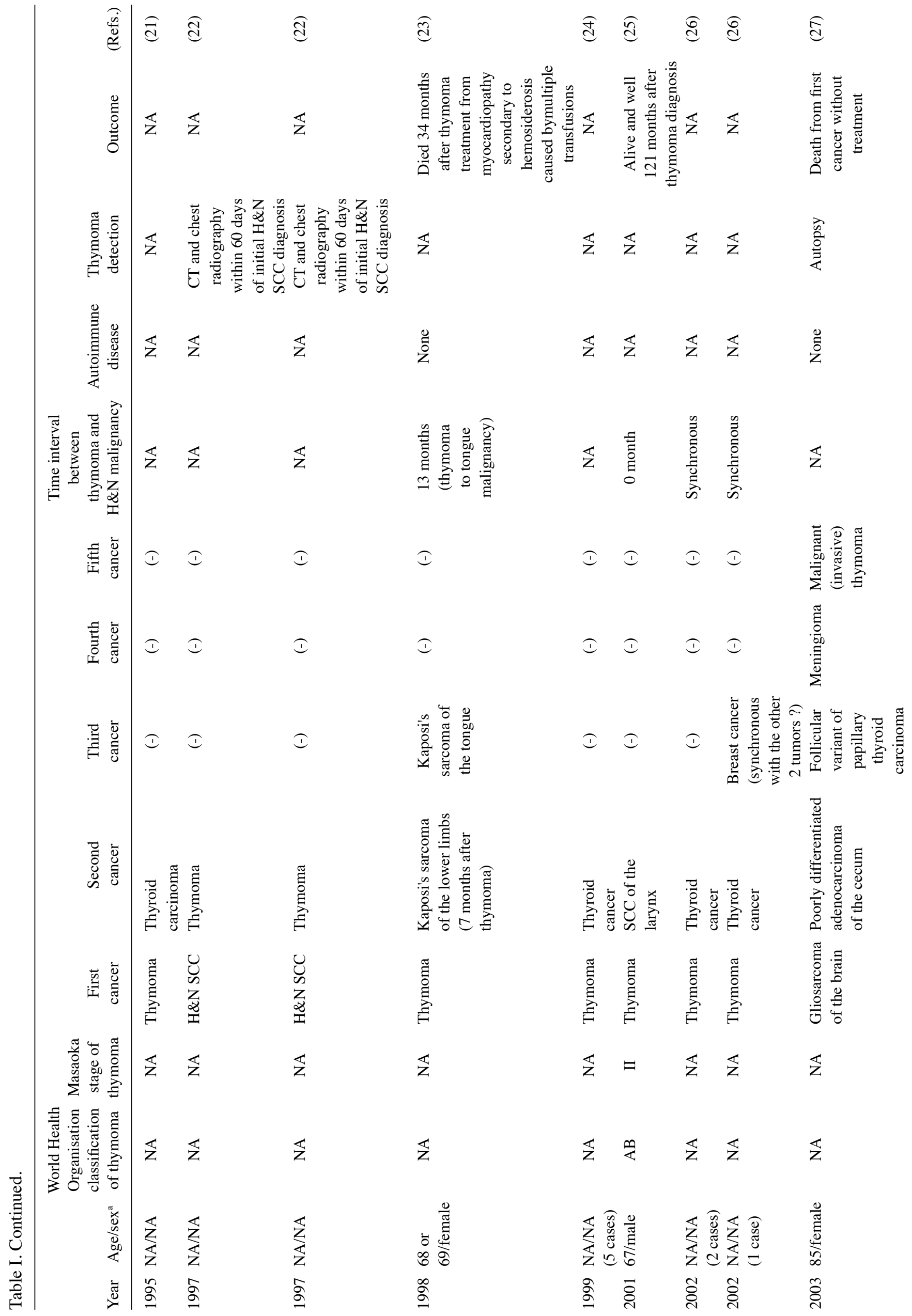




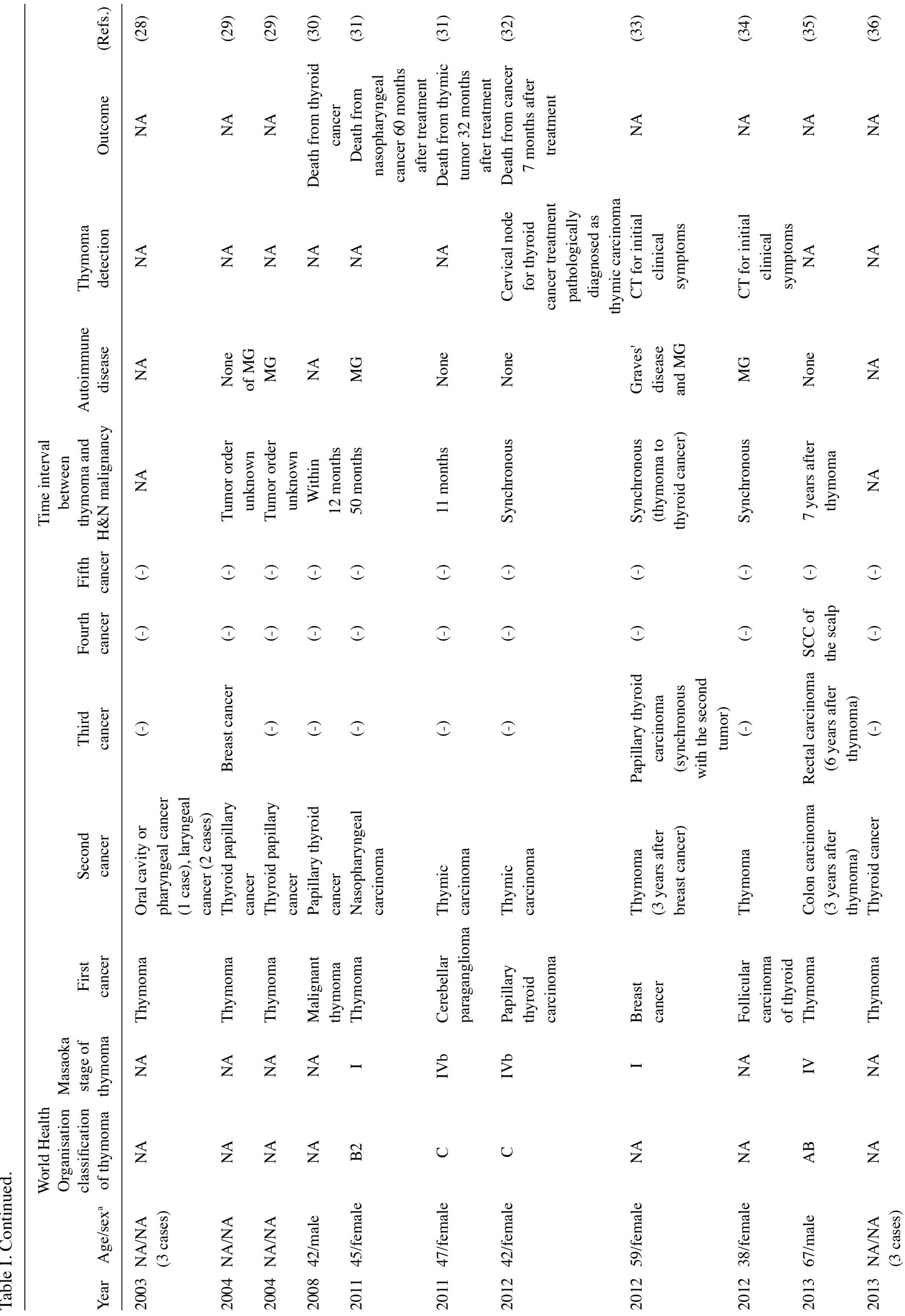




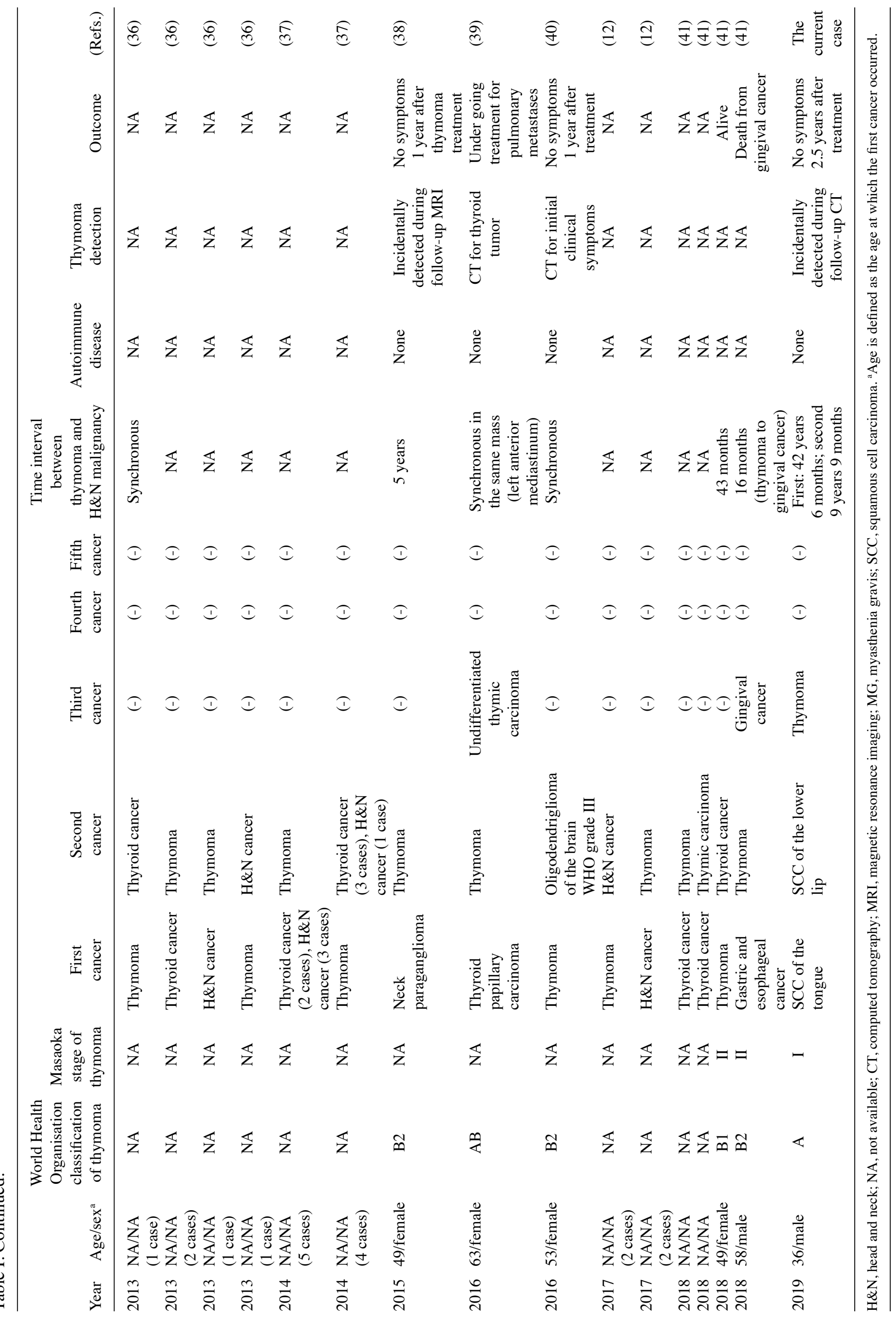


thymoma is a relatively slow growing tumor and therefore, it tends to be asymptomatic for long periods. Hence, its initial detection often occurs incidentally by imaging. ii) Thymic carcinoma can occur within the thymoma (40,46-48), which also worsens prognosis (49). For instance, Kuo and Chan (49) have reported that four of five thymoma cases progressing to thymic carcinoma died within 15 months. Karino et al (39) have performed the clonality analysis of coexisting thymoma and thymic carcinoma and suggested transformation from a preexisting thymoma to a malignant tumor. iii) Thymoma is associated with several potentially fatal diseases, particularly autoimmune diseases such as myasthenia gravis (MG) arising as a paraneoplastic syndrome (50-53). Therefore, early thymoma detection is crucial for clinicians.

Thymoma is a rare tumor, with reported incidence of only 0.13 per 100,000 person-years in the United States according to the Surveillance Epidemiology End Results (SEER) program (54). Actually, the incidence of thymoma is low and varies between countries $(54,55)$. However, through the case, we recommend the lifelong follow-up using CT in patients with $\mathrm{H} \& \mathrm{~N}$ cancer for three reasons. One, the person-years of all individuals in the countries was low; on the other hand, in patients with $H \& N$ cancer, there was a significant occurrence of thymoma (56). Two, as described above, thymoma should be detected and treated as soon as possible. Three, for patients with H\&N cancer, SPT (any type of tumor) tends to occur particularly in the 'H\&N, lung, and esophagus' and to develop for long periods (such as $\geq 10$ years) after the treatment $(2,57)$. However, no guidelines for lifelong follow-up using CT exist to date (5). Therefore, for patients with H\&N cancer, CT facilitates the detection of all other SPTs as well as thymomas.

Patients with thymoma, however, frequently develop a subsequent (synchronous and metachronous) SPT, i.e., 'SPT following thymoma,' which has been well reported to date $(12,13,28,36,37,42,56,58-62)$. Those studies were conducted to manage patients with thymoma. Alternatively, there are relatively fewer reports of 'SPT before thymoma' (similar to the present case of H\&N cancer), and those reports did not regard 'SPT before thymoma' as important $(12,36,37,42,56,59,61)$. However, 'SPT before thymoma' has significantly occurred in patients with $H \& N$ cancer (56), indicating that thymoma has significantly occurred as SPT in patients with $H \& N$ cancer. Therefore, to determine the new management protocol for patients with H\&N cancer, we postulated that there was greater number of hidden 'SPTs before thymoma' cases than we have noticed to date.

Despite being a rare disease, thymoma tends to occur as an SPT in patients with H\&N cancer, as described above. In the current case, thymoma was incidentally detected using CT during follow-up 9 years after SCC of the lip. During post-treatment follow-up of patients with $\mathrm{H} \& \mathrm{~N}$ cancer, CT can be used to detect SPTs as well as cancer recurrence and metastasis (63). However, the National Comprehensive Cancer Network guidelines for long-term radiological follow-up of $\mathrm{H} \& \mathrm{~N}$ cancer are ambiguous (5). In most cases in Table I, the time interval between thymoma and $H \& N$ malignancy was synchronized; however, some previous cases of thymoma as well as the present case, were diagnosed as SPT $>5$ years after the preceding cancer (Table I) $(17,38)$. The current patient exhibited three risk factors for SPT. First, SPT can be induced by radiotherapy and/or chemotherapy (64). The patient had received the postoperative radiotherapy for SCC of the tongue and neck metastasis. The radiotherapy might have induced the second lip cancer (65). Second, he was a former heavy smoker and former frequent drinker $(64,66)$. Finally, the patient had a family history of cancer $(67,68)$. However, thymoma as SPT is not applicable to these theories because the underlying cause of the occurrence of thymoma remains unknown owing to its rarity $(51,54,69)$. On the other hand, thymoma is related to autoimmune diseases such as MG $(50,56)$. However, the present patient did not have any autoimmune disease, including MG. Furthermore, thymoma is associated with lichen planus (70); however, the patient exhibited no clinical or pathological lesions indicative of lichen planus. Through our literature review, we attempted to identify possible reasons for thymoma following other extrathymic cancers, but previous cases show no common characteristics (see also Table IV of Engels) (54).

Further, the SPT of thymoma has been well discussed in recent papers $(71,72)$. Theories on the causes of extrathymic tumor before or after thymoma have also been debated till date. Thymoma itself is associated with SPTs $(25,41,56,73)$, and several patients with thymoma succumb to subsequent SPTs as well as to thymoma recurrence and metastasis or related autoimmune diseases (74). Therefore, 'SPTs following thymoma' is widely recognized as a critical issue. In contrast, 'SPT before thymoma' is rare and there has been relatively little investigation of possible causes, even in studies documenting such cases $(12,36,37,41,42,56,60,61,75,76)$. Evidently, 'SPT before thymoma' is unrelated to thymoma therapy and not directly caused by thymoma itself $(35,54,73)$. Travis et al (59) have reported a non-significant odds ratio for 'SPTs before thymoma' based on SEER program data from 1973 to 2000 $(\mathrm{O} / \mathrm{E}=1.33 ; 95 \% \mathrm{CI}=1.0-1.73 ; \mathrm{O}=56)$. On the other hand, several studies have described 'SPT before thymoma' as well as 'following thymoma' $(56,61,77)$. It has been suggested that 'SPT before thymoma' arises from the dysfunction of cortical thymic epithelial cells in nascent thymoma without clinical symptoms (61). This theory is based on observations that the time interval from SPT to thymoma diagnosis is significantly shorter than that for other sequential cancers (61). Alternatively, Filosso et al (36) have suggested that the autoimmunity disorder associated with thymoma may cause prior SPTs. In the present patient, however, thymoma occurred 9 years 9 months after SCC of the lip (also, 42 years and 6 months after SCC of the tongue); therefore, these explanations are unlikely. Another study has reported that SPT was diagnosed at 6.8 \pm 5.9 years (median, 5 years; range 1-29 years) prior to thymoma diagnosis (56). Further, the occurrence of 'SPTs before thymoma' has significantly been reported in patients with H\&N cancer (56). However, the authors did not describe the reason for such frequent occurrence. Thymoma itself is a rarely occurring lesion; therefore, the clinical information of 'SPTs before thymoma' cases is required to determine the hint of the occurence. For example, $H \& N$ cancer is sometimes treated with radiotherapy such as in our case. We hypothesized that the radiotherapy of H\&N or chest lesion may have affected the thymus. To understand the reason underlying the occurrence of subsequent thymoma in patients with $H \& N$ cancer and to detect the risk factor, we summarized the 'H\&N cancer followed by thymoma' cases in Table II. The current case 


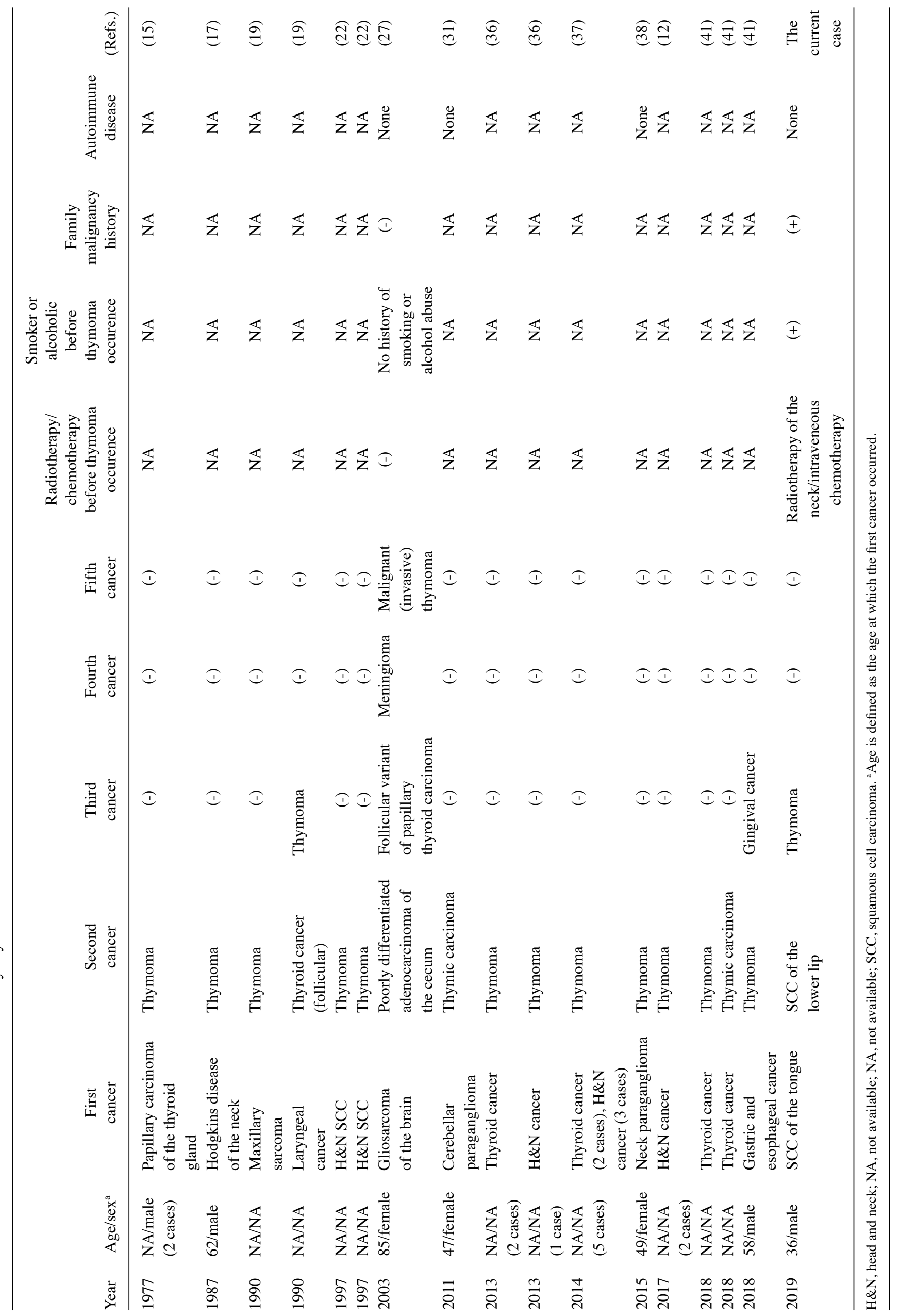

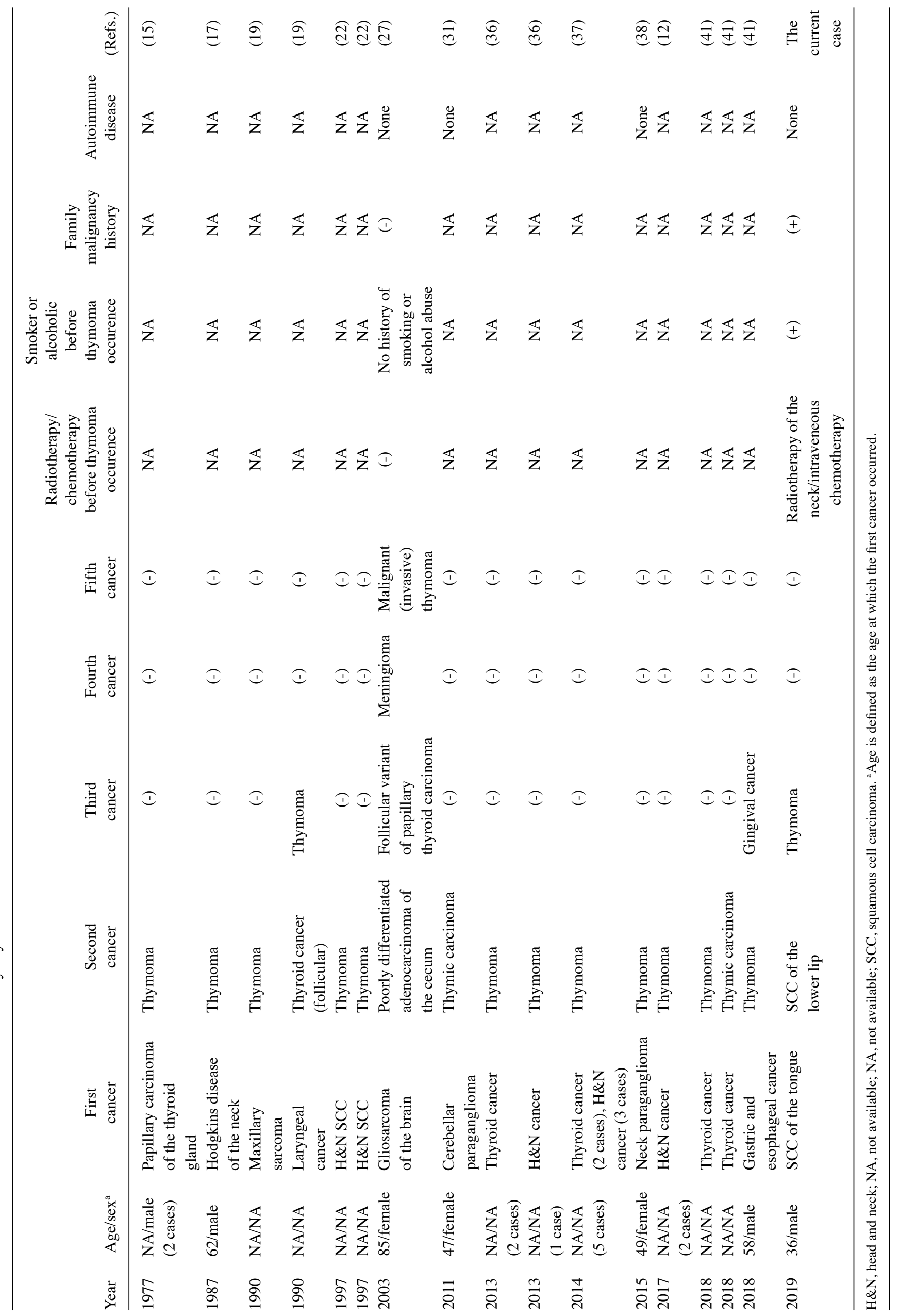

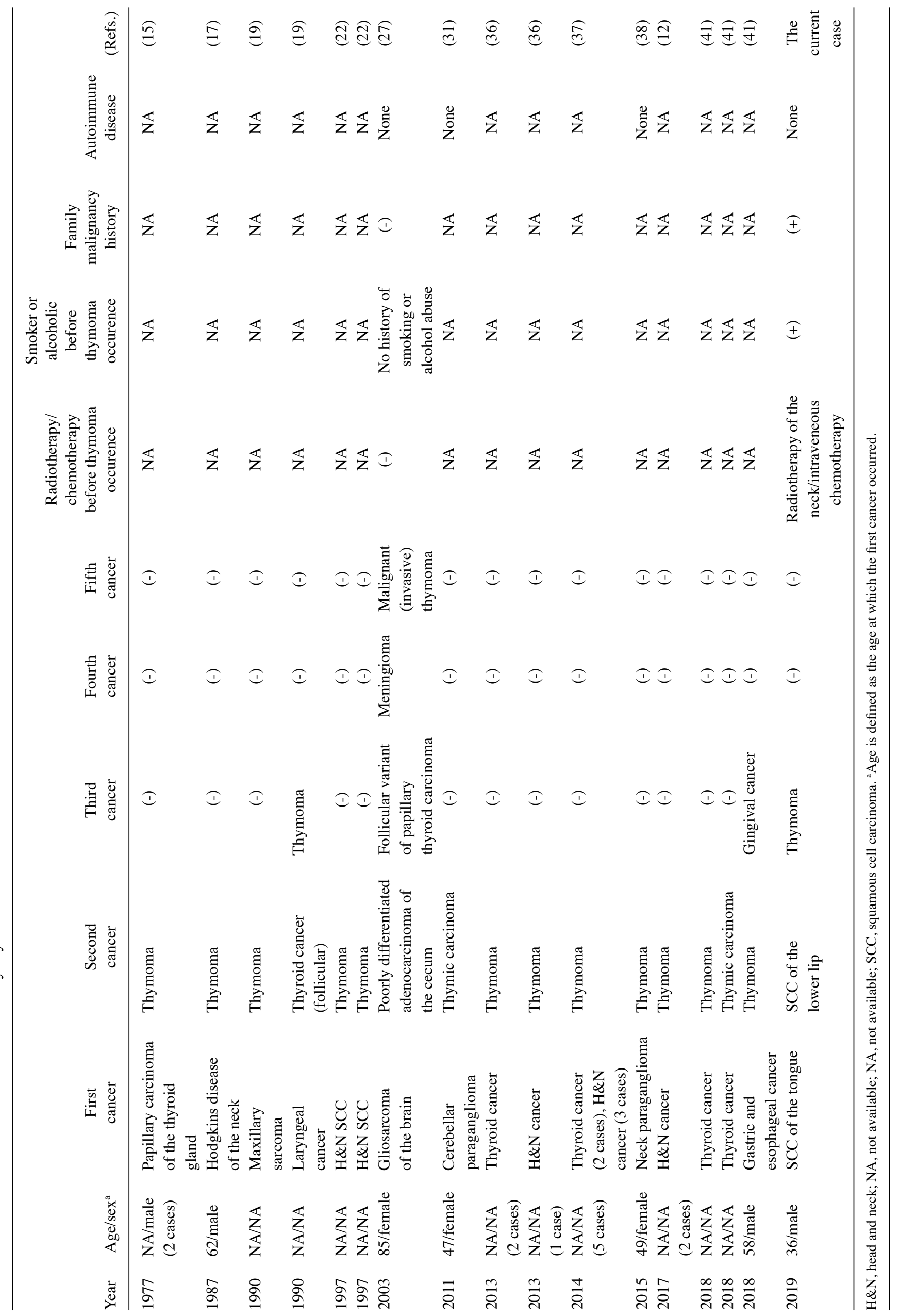

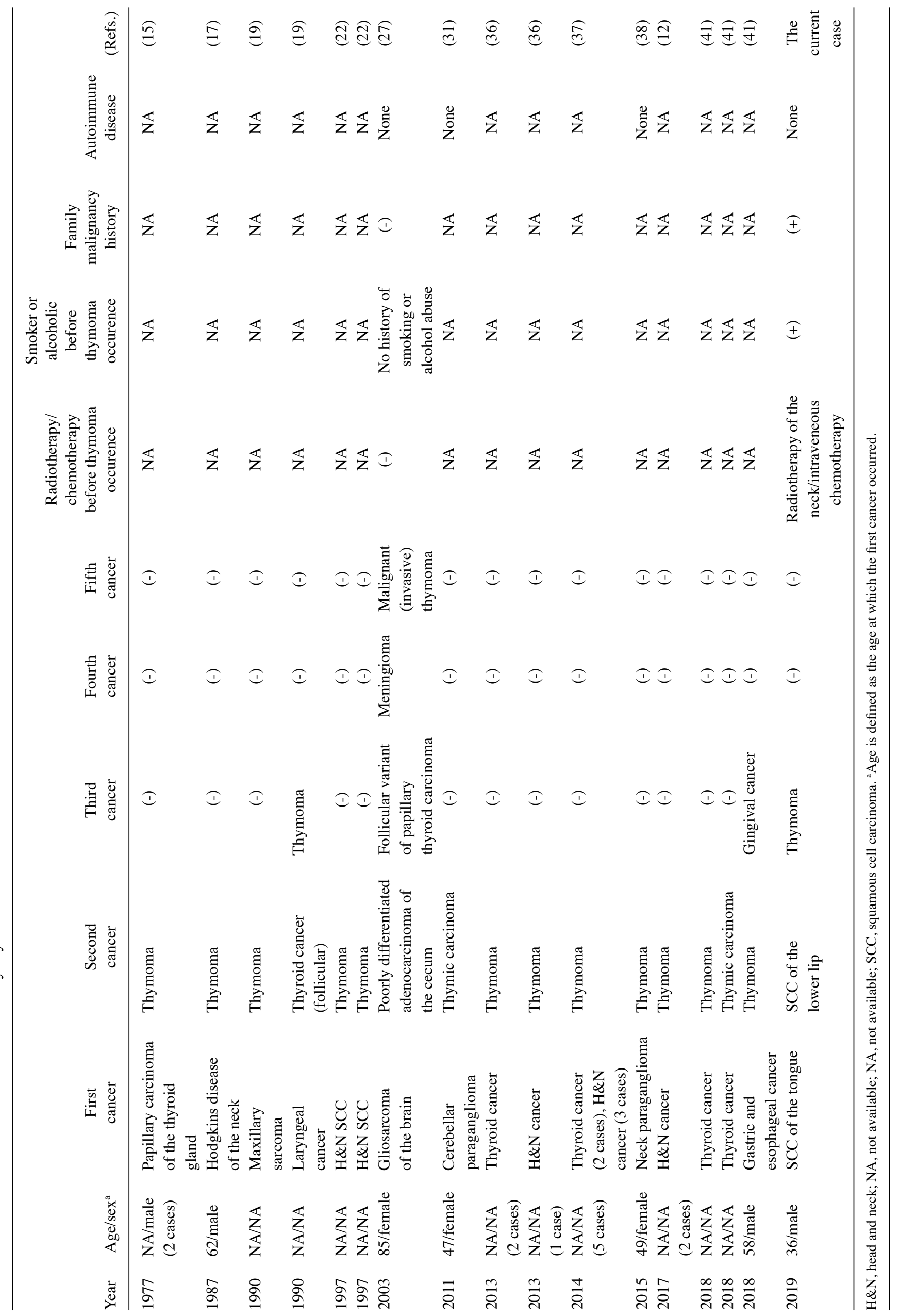

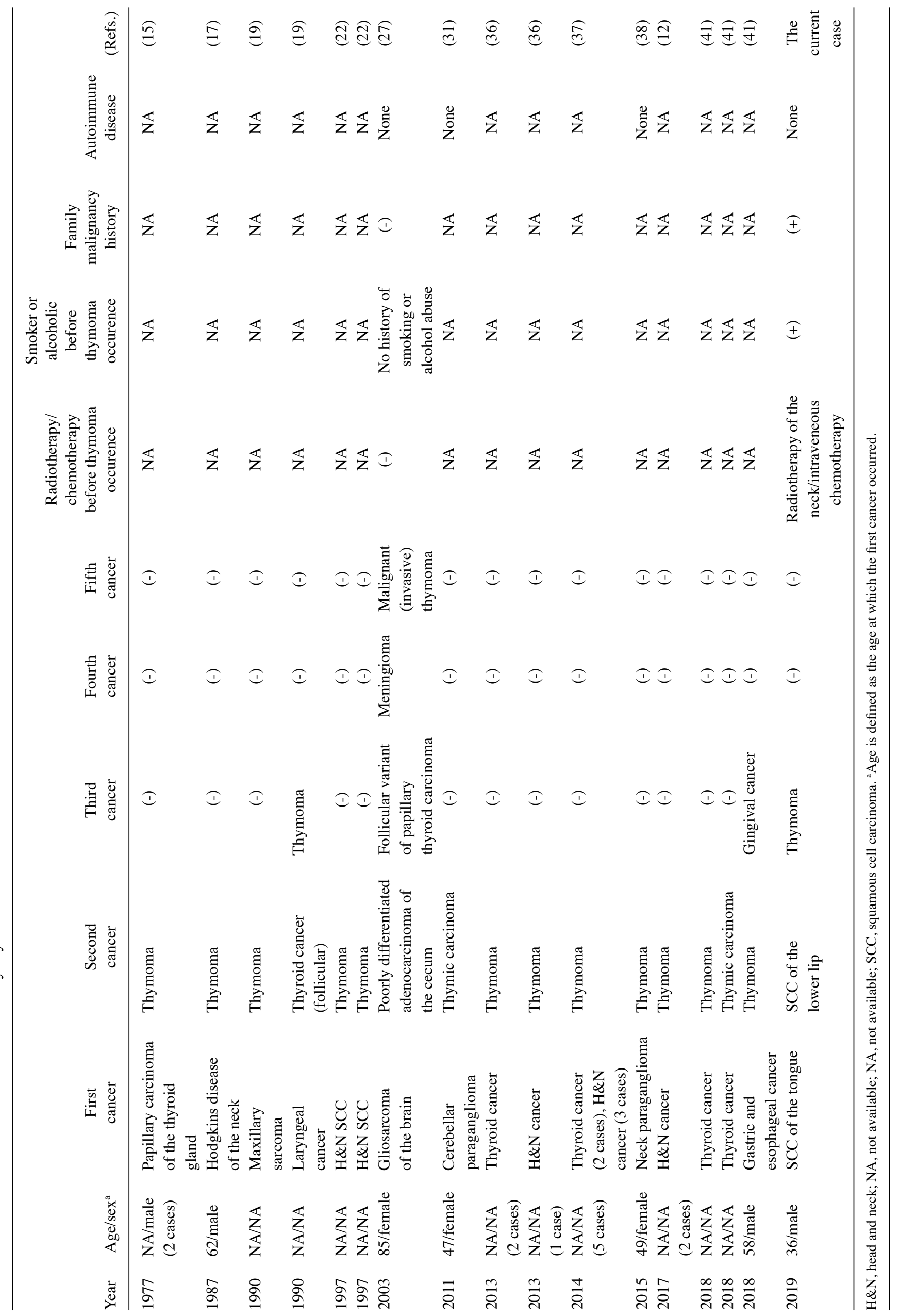


was the first on 'thymoma following H\&N cancer' wherein the patient has a history of radiotherapy or chemotherapy, smoking, drinking, and family members with cancer. On the other hand, we were unable to confirm the clinical information of other reported patients $(16,27)$. Therefore, we could not perform statistical analysis considering the limited clinical information. Additional cases with well-described clinical information are required to detect the etiology of 'thymoma following H\&N cancer.' According to the summary in Table I, the time interval between ' $\mathrm{H} \& \mathrm{~N}$ cancer before thymoma' and thymoma diagnosis ranges from 0 to 7 years $(17,19,31,38,41)$ including several cases occurring 5 to 7 years before thymoma. Therefore, although the etiology remains uncertain, long-term follow-up appears vital for patients with $\mathrm{H} \& \mathrm{~N}$ cancer to detect subsequent thymoma.

The patient initially refused to treat the thymoma because experienced stress owing to the numerous examinations, such as CT, FDG-PET, and gastroendoscopy. For patients with $H \& N$ cancer, the risk of SPT significantly increased (2). Further, despite the medical advances for controlling the index $\mathrm{H} \& \mathrm{~N}$ cancer, SPT currently poses a high mortality risk for the patients $(2,78)$. To date, in numerous SPT cases, risk factors, such as treatment (radiotherapy, chemotherapy) for index cancer, environmental factor (e.g., smoking, alcohol consumption), or HPV infection, have been reported $(64,79)$. The mechanism (in terms of genomics and proteomics) of SPTs in patients with $\mathrm{H} \& \mathrm{~N}$ cancer is crucial and has been well analyzed and reported. For example, Bunbanjerdsuk et al have analyzed the oncoproteomics and gene expression and reported ITPR 3, KMT2D, and EMILINI as prognostic factors in SPT for patients with H\&N cancer (80). da Silva et al have reported that epithelial-mesenchymal transition markers such as E-cadherin and beta-catenin, exhibit a significant prognostic impact in multiple primary oral SCC cases (81). Sun $e$ al have suggested that Fas and FasL polymorphisms may modify SPT risk in oropharyngeal or other types of H\&N SCC (82). Those studies were conducted to achieve better patient outcomes. Moreover, we strongly suggest that patient background is an important prognostic factor. To date, the cases with $\geq 3$ SPTs, including H\&N cancer (similar to our case), have also been well reported, and one of the reasons for the poor outcome was 'patient's refusal for examination or treatment' (83). Guy et al have reported that lost productivity costs was higher for cancer survivors than for individuals without cancer history and that such economic burden may affect the management of SPTs (84). Moreover, there are several types of stress for cancer survivors $(84,85)$. In the current case, the tongue or lip could be directly examined; however the other sites of the $\mathrm{H} \& \mathrm{~N}$, lung, and esophagus must be examined using approaches such as CT, PET, and gastroendoscopy. The patient might experience stress from those examinations as described above.

Limitations of our study include the retrospective design and the absence of additional case patients. In addition, our literature review was based on only two search services, PubMed and Google Scholar; therefore, additional cases may yet emerge. Nonetheless, this case report may enhance the clinical awareness of possible thymoma years after $\mathrm{H} \& \mathrm{~N}$ cancer and provide beneficial information for thymoma detection.
In conclusion, we report a case with a previously undocumented combination of tumors. To ensure that the presence of thymomas in patients with H\&N cancer is not overlooked, we suggest regular lifelong follow-up using contrast-enhanced CT. Our literature review revealed that thymomas significantly occur in patients with H\&N cancer, and similar to other SPTs, thymomas should be detected as soon as possible to increase the chances of successful treatment outcome.

\section{Acknowledgements}

Not applicable.

\section{Funding}

No funding was received.

\section{Availability of data and materials}

All data generated or analyzed during this study are included in this published article.

\section{Authors' contributions}

NM and TM acquired the data, performed the literature review and edited the manuscript. TM and AA substantially contributed to the concept and design of the study. TS, TN, TT, AMata, $\mathrm{JF}, \mathrm{YK}$ and $\mathrm{KN}$ acquired the data and provided clinical advice. AA revised the manuscript. AMats, KK and NY evaluated the specimens and provided histopathological advice. TM played a major role in preparation of the manuscript. All authors read and approved the final manuscript.

\section{Ethics approval and consent to participate}

The report was submitted for ethical review to the Ethics Committee of the University of the Ryukyus (Okinawa, Japan), who waived the requirement for review per institutional protocol owing to the study not containing content that requires ethical approval. The Ethics Committee approved the submission and publication of the manuscript.

\section{Patient consent for publication}

Written informed consent was obtained from the patient for the publication of this case report and the accompanying images.

\section{Competing interests}

The authors declare that they have no competing interests.

\section{References}

1. Ko HH, Cheng SL, Lee JJ, Chen HM, Wang CW, Cheng SJ and Kok SH: Factors influencing the incidence and prognosis of second primary tumors in patients with oral squamous cell carcinoma. Head Neck 38: 1459-1466, 2016.

2. Morris LG, Sikora AG, Hayes RB, Patel SG and Ganly I: Anatomic sites at elevated risk of second primary cancer after an index head and neck cancer. Cancer Causes Control 22: 671-679, 2011. 
3. Brands MT, Brennan PA, Verbeek ALM, Merkx MAW and Geurts SME: Follow-up after curative treatment for oral squamous cell carcinoma. A critical appraisal of the guidelines and a review of the literature. Eur J Surg Oncol 44: 559-565, 2018.

4. Mehra R, Seiwert TY, Gupta S, Weiss J, Gluck I, Eder JP, Burtness B, Tahara M, Keam B, Kang H, et al: Efficacy and safety of pembrolizumab in recurrent/metastatic head and neck squamous cell carcinoma: Pooled analyses after long-term follow-up in KEYNOTE-012. Br J Cancer 119: 153-159, 2018.

5. NationalComprehensive CancerNetwork:Headand Neck Cancers Version 2, 2018. https://www.nccn.org/professionals/physician gls/pdf/head-and-neck.pdf. Accessed October 22, 2018.

6. Sobin LH and Wittekind C (eds): International Union against cancer: TNM Classification of Malignant Tumours. 6th edition. Wiley-Liss, New York, NY, 2002.

7. Licitra L, Grandi C, Guzzo M, Mariani L, Lo Vullo S, Valvo F, Quattrone $\mathrm{P}$, Valagussa $\mathrm{P}$, Bonadonna G, Molinari R and Cantù G: Primary chemotherapy in resectable oral cavity squamous cell cancer: A randomized controlled trial. J Clin Oncol 21: 327-333, 2003.

8. Yamamoto E, Kohama G, Sunakawa H, Iwai M and Hiratsuka H: Mode of invasion, bleomycin sensitivity, and clinical course in squamous cell carcinoma of the oral cavity. Cancer 51: 2175-2180, 1983.

9. Moertel CG, Dockerty MB and Baggenstoss AH: Multiple primary malignant neoplasms. I. Introduction and presentation of data. Cancer 14: 221-230, 1961.

10. Warren S and Gates O: Multiple primary malignant tumors: A survey of the literature and a statistical study. Am J Cancer 16: 1358,1932

11. Cooper A (ed.): The Anatomy of the Thymus Gland. Longman, London, Rees, Orme, Green, and Brown, London, 1832.

12. Kamata T, Yoshida S, Wada H, Fujiwara T, Suzuki H, Nakajima T, Iwata T, Nakatani Y and Yoshino I: Extrathymic malignancies associated with thymoma: A forty-year experience at a single institution. Interact Cardiovasc Thorac Surg 24: 576-581, 2017.

13. Souadjian JV, Silverstein MN and Titus JL: Thymoma and cancer. Cancer 22: 1221-1225, 1968

14. Lattes R: Thymoma and other tumors of the thymus. An analysis of 107 cases. Cancer 15: 1224-1260, 1962.

15. LeGolvan DP and Abell MR: Thymomas. Cancer 39: 2142-2157, 1977.

16. Donaldson JO, Grunnet ML and Thompson HG: Concurrence of myasthenia gravis, thymoma, and thyroid carcinoma. Arch Neurol 40: 122-124, 1983

17. Nemoto K, Ishikawa H, Ohnishi Y, Nakamura T and Ohsaki N: Hodgkin's disease accompanied with thymoma. Acta Patho Jpn 37: 1505-1512, 1987.

18. Rothberg MS, Eisenbud L and Griboff S: Chronic mucocutaneous candidiasis-thymoma syndrome. A case report. Oral Surg Oral Med Oral Pathol 68: 411-413, 1989.

19. Couture MM and Mountain CF: Thymoma. Semin Surg Oncol 6 : $110-114,1990$

20. Senga O, Hikita H, Kinoshita T, Hara K and Miyakawa M Myasthenia gravis with thymoma associated with occult thyroid carcinoma. Surg Today 22: 66-68, 1992.

21. Blumberg D, Port JL, Weksler B, Delgado R, Rosai J, Bains MS Ginsberg RJ, Martini N, McCormack PM, Rusch V, et al: Thymoma: A multivariate analysis of factors predicting survival. Ann Thorac Surg 60: 908-913, 1995

22. Reiner B, Siegel E, Sawyer R, Brocato RM, Maroney M and Hooper F: The impact of routine CT of the chest on the diagnosis and management of newly diagnosed squamous cell carcinoma of the head and neck. AJR Am J Roentgenol 169: 667-671, 1997.

23. Perez E, Barnadas MA, Garcia-Patos V, Pedro C, Curell R Sander CA, Kind P, de Moragas JM and Alomar A: Kaposi's sarcoma in a patient with erythroblastopenia and thymoma: Reactivation after topical corticosteroids. Dermatology 197 264-267, 1998.

24. Wilkins KB, Sheikh E, Green R, Patel M, George S, Takano M, Diener-West M, Welsh J, Howard S, Askin F and Bulkley GB Clinical and pathologic predictors of survival in patients with thymoma. Ann Surg 230: 562-572, 1999.

25. Pan CC, Chen PC, Wang LS, Chi KH and Chiang H: Thymoma is associated with an increased risk of second malignancy. Cancer 92: 2406-2411, 2001.

26. Evoli A, Minisci C, Di Schino C, Marsili F, Punzi C, Batocchi AP, Tonali PA, Doglietto GB, Granone P, Trodella L, et al: Thymoma in patients with MG-Characteristics and long-term outcome. Neurology 59: 1844-1850, 2002.
27. Welsh JS, Thurman SA and Howard SP: Thymoma and multiple malignancies: A case of five synchronous neoplasms and literature review. Clin Med Res 1: 227-232, 2003.

28. Engels EA and Pfeiffer RM: Malignant thymoma in the United States: Demographic patterns in incidence and associations with subsequent malignancies. Int J Cancer 105: 546-551, 2003.

29. Evoli A, Punzi C, Marsili F, Di Schino C, Cesario A, Galetta D, Margaritora S and Granone P: Extrathymic malignancies in patients with thymoma. Ann Oncol 15: 692-693, 2004.

30. Omu O, Ozcan Z, Yazici B, Akgun A, Oral A and Ozkilic H: Multiple primary tumors in differentiated thyroid carcinoma and relationship to thyroid cancer outcome. Endocr J 55: 365-372, 2008.

31. Yen YT, Lai WW, Wu MH, Lin MY, Chang JM, Hsu IL and Tseng YL: Thymic neuroendocrine carcinoma and thymoma are both associated with increased risk of extrathymic malignancy: A 20-year review of a single institution. Ann Thorac Surg 91: 219-225, 2011.

32. Doumasa S, Ioannis A, Voutsadakisb d, Fourkasc $\mathrm{N}$ Papagiannic M and Papandreou CN: Concomitant thymic carcinoma with cervical and supraclavicular node metastases and thyroid carcinoma: Report of a case and literature review. J Med Cases 3: 181-184, 2012.

33. Anzai T, Yokoyama J, Ohba S, Ito S, Fujimaki M, Kojima M and Ikeda K: An important initial diagnosis of a patient with Graves' disease associated with myasthenia gravis, thyroid carcinoma, and thymoma. Head Neck Oncol 4: 56, 2012.

34. $\mathrm{Ni} \mathrm{H}$ and Htet A: Follicular thyroid carcinoma in a patient with myasthenia gravis and thymoma: A rare association. Ecancermedicalscience 6: 274, 2012 .

35. Thongprayoon C, Tantrachoti $\mathrm{P}$, Phatharacharukul $\mathrm{P}$, Buranapraditkun S and Klaewsongkram J: Associated immunological disorders and cellular immune dysfunction in thymoma: A study of 87 cases from Thailand. Arch Immunol Ther Exp (Warsz) 61: 85-93, 2013.

36. Filosso PL, Galassi C, Ruffini E, Margaritora S, Bertolaccini L, Casadio C, Anile M and Venuta F: Thymoma and the increased risk of developing extrathymic malignancies: A multicentre study. Eur J Cardiothorac Surg 44: 219-224, 2013.

37. Filosso PL, Venuta F, Oliaro A, Ruffini E, Rendina EA, Margaritora S, Casadio C, Terzi A, Rena O, Lococo F and Guerrera F: Thymoma and inter-relationships between clinical variables: A multicentre study in 537 patients. Eur J Cardiothorac Surg 45: 1020-1027, 2014

38. Bano G, Sennik D, Kenchaiah M, Kyaw Y, Snape K, Tripathi V, Wilson P, Vlahos I, Hunt I and Hodgson S: A case of co-existing paraganglioma and thymoma. Springerplus 4: 632, 2015.

39. Karino F, Yokose T, Matsukuma S, Miyagi Y, Murakami S, Ito H, Nakayama $\mathrm{H}$ and Yamada K: Clonality analysis performed using human androgen receptor assay in a rare case of undifferentiated thymic carcinoma coexisting with type AB thymoma. Pathol Int 66: 398-403, 2016

40. Vaziri M and Rad K: Synchronous thymoma and oligodendroglioma: A rare association. Int J Surg Case Rep 21: 95-98, 2016.

41. Hamaji M, Kawaguchi A, Omasa M, Nakagawa T, Sumitomo R, Huang CL, Fujinaga T, Ikeda M, Shoji T, Katakura H, et al: Low incidence of and mortality from a second malignancy after resection of thymic carcinoma. Interact Cardiovasc Thorac Surg 28: 375-379, 2018

42. Mariano C, Ionescu DN, Cheung WY, Ali RH, Laskin J, Evans K, Carolan $\mathrm{H}$ and Murray N: Thymoma: A population-based study of the management and outcomes for the province of British Columbia. J Thorac Oncol 8: 109-117, 2013.

43. Johnson SB, Eng TY, Giaccone G and Thomas CR Jr: Thymoma: Update for the new millenium. The Oncologist 6: 239-246, 2001.

44. Okumura M, Ohta M, Tateyama $\mathrm{H}$, Nakagawa $\mathrm{K}$, Matsumura A, Maeda $\mathrm{H}$, Tada $\mathrm{H}$, Eimoto T, Matsuda $\mathrm{H}$ and Masaoka A: The World Health Organization histologic classification system reflects the oncologic behavior of thymoma: A clinical study of 273 patients. Cancer 94: 624-632, 2002.

45. Okumura $M$, Shiono $H$, Minami $M$, Inoue $M$, Utsumi $T$, Kadota Y and Sawa Y: Clinical and pathological aspects of thymic epithelial tumors. Gen Thorac Cardiovasc Surg 56: 10-16, 2008.

46. Hosaka Y, Tsuchida M, Umezu H, Eimoto T, Hashimoto T, Shinohara $\mathrm{H}$ and Hayashi J: Primary thymic adenocarcinoma coexisting with type $\mathrm{AB}$ thymoma: A rare case with long-term survival. Gen Thorac Cardiovasc Surg 58: 488-491, 2010 
47. Hsu NY, Lin JW, Hsieh MJ, Lai YF, Kao CL and Chang JP: Thymic lymphoepithelioma-like carcinoma associated with thymoma in a patient with ocular myasthenia. Scand Cardiovasc J 32: 105-107, 1998.

48. Suster S and Moran CA: Primary thymic epithelial neoplasms showing combined features of thymoma and thymic carcinoma. A clinicopathologic study of 22 cases. Am J Surg Pathol 20: 1469-1480, 1996.

49. Kuo TT and Chan JK: Thymic carcinoma arising in thymoma is associated with alterations in immunohistochemical profile. Am J Surg Pathol 22: 1474-1481, 1998.

50. Evoli A, Minicuci GM, Vitaliani R, Battaglia A, Della Marca G, Lauriola L and Fattorossi A: Paraneoplastic diseases associated with thymoma. J Neurol 254: 756-762, 2007.

51. Venuta F, Rendina EA, Anile M, de Giacomo T, Vitolo D and Coloni GF: Thymoma and thymic carcinoma. Gen Thorac Cardiovasc Surg 60: 1-12, 2012.

52. Gong L, Zhang P, Liu XY and Fang M: A rare thymoma case with seven paraneoplastic syndromes. Int J Clin Exp Med 8: 19517-19523, 2015.

53. Qiao J, Zhou G, Ding Y, Zhu D and Fang H: Multiple paraneoplastic syndromes: Myasthenia gravis, vitiligo, alopecia areata and oral lichen planus associated with thymoma. J Neurol Sci 308: 177-179, 2011.

54. Engels EA: Epidemiology of thymoma and associated malignancies. J Thorac Oncol 5 (Suppl 4): S260-S265, 2010.

55. Jeong DY, Lee KS, Chung MJ, Zo JI, Shim YM and Moon JW: JOURNAL CLUB: Doubling time of thymic epithelial tumors correlates with world health organization histopathologic classification. AJR Am J Roentgenol 209: W202-W210, 2017.

56. Weksler B, Nason KS, Mackey D, Gallagher A and Pennathur A: Thymomas and extrathymic cancers. Ann Thorac Surg 93: 884-888, 2012

57. CurtisRE,Freedman DM,RonE,RiesLAG,HackerDG,Edwards BK, Tucker MA and Fraumeni JF Jr (eds): New malignancies among cancer survivors: SEER Cancer Registries, 1973-2000. National Cancer Institute. NIH Publ. No. 05-5302. Bethesda, MD, 2006. https://seer. cancer.gov/archive/publications/mpmono/MPMonograph_complete. pdf. Accessed March 17, 2019.

58. Gadalla SM, Rajan A, Pfeiffer R, Kristinsson SY, Bjorkholm M, Landgren $\mathrm{O}$ and Giaccone G: A population-based assessment of mortality and morbidity patterns among patients with thymoma. Int J Cancer 128: 2688-2694, 2011.

59. Travis LB, Boice JD Jr and Travis WD: Second primary cancers after thymoma. Int J Cancer 107: 868-870, 2003

60. Welsh JS, Wilkins KB, Green R, Bulkley G, Askin F, Diener-West $M$ and Howard SP: Association between thymoma and second neoplasms. JAMA 283: 1142-1143, 2000.

61. Granato F, Ambrosio MR, Spina D, Lazzi S, Rocca BJ, Voltolini L, Bongiolatti S, Luzzi L, Gotti G, Leoncini L and Tosi P: Patients with thymomas have an increased risk of developing additional malignancies: Lack of immunological surveillance? Histopathology 60: 437-442, 2012.

62. Basta I,Pekmezovic T,Peric S,Nikolic A,Rakocevic-Stojanovic V, Stevic Z, Marjanovic I and Lavrnic D: Extrathymic malignancies in a defined cohort of patients with myasthenia gravis. J Neurol Sci 346: 80-84, 2014.

63. Maruyama T, Nakasone T, Maruyama N, Matayoshi A and Arasaki A: Synchronous quadruple multiple primary cancers of the tongue, bilateral breasts, and kidney in a female patient with a disease-free survival time of more than 5 years: A case report. World J Surg Oncol 13: 263, 2015.

64. Babacan NA, Aksoy S, Cetin B, Ozdemir NY, Benekli M, Uyeturk U, Ali Kaplan M, Kos T, Karaca H, Oksuzoglu B, et al: Multiple primary malignant neoplasms: Multi-center results from Turkey. J BUON 17: 770-775, 2012.

65. Martin OA, Yin X, Forrester HB, Sprung CN and Martin RF: Potential strategies to ameliorate risk of radiotherapy-induced second malignant neoplasms. Semin Cancer Biol 37-38: 65-76, 2016.

66. Kotnis A, Namkung J, Kannan S, Jayakrupakar N, Park T, Sarin R and Mulherkar R: Multiple pathway-based genetic variations associated with tobacco related multiple primary neoplasms. PLoS One 7: e30013, 2012.

67. Hung CY, Ueng SH, Lin YC and Chou WC: Metastatic carcinoma of the urinary bladder in a 67-year-old female with underlying triple primary cancers. Journal of Cancer Research and Practice 3: 49-53, 2016.
68. Forrest J, Slaney G, Crocker J, Hallam J and Taylor AM: Multiple malignancy with a familial tendency. Clin Oncol 7: 357-364, 1981.

69. Travi WD, Brambilla E, Burke AP, Marx A and Nicholson AG: WHO classification of tumours of the lung, pleura, thymus and heart. IARC Press , Lyon, France. Volume 7. 4th edition. 2015.

70. Motegi S, Uchiyama A, Yamada K, Toki S, Amano H and Ishikawa O: Lichen planus complicated with thymoma: Report of three Japanese cases and review of the published work. J Dermatol 42: 1072-1077, 2015.

71. Mou H, Liao Q, Hou X, Chen T and Zhu Y: Clinical characteristics, risk factors, and outcomes after adjuvant radiotherapy for patients with thymoma in the United States: Analysis of the surveillance, epidemiology, and end results (SEER) registry (1988-2013). Int J Radiat Biol 94: 495-502, 2018.

72. Hamaji M, Sozu T, Machida R, Omasa M, Menju T, Aoyama A, Sato T, Chen-Yoshikawa TF, Sonobe M and Date H: Second malignancy versus recurrence after complete resection of thymoma. Asian Cardiovasc Thorac Ann 26: 290-295, 2018.

73. Scorsetti M, Leo F, Trama A, D'Angelillo R, Serpico D, Macerelli M, Zucali P, Gatta G and Garassino MC: Thymoma and thymic carcinomas. Crit Rev Oncol Hematol 99: 332-350, 2016.

74. Huang J, Detterbeck FC, Wang Z and Loehrer PJ Sr: Standard outcome measures for thymic malignancies. J Thorac Oncol 5: 2017-2023, 2010.

75. Masaoka A, Yamakawa Y, Niwa H, Fukai I, Saito Y, Tokudome S, Nakahara $\mathrm{K}$ and Fujii Y: Thymectomy and malignancy. Eur J Cardiothorac Surg 8: 251-253, 1994.

76. Owe JF, Cvancarova M, Romi F and Gilhus NE: Extrathymic malignancies in thymoma patients with and without myasthenia gravis. J Neurol Sci 290: 66-69, 2010.

77. Szolkowska M, Langfort R, Winiarski S, Zaremba J, Prochorec-Sobieszek M, Rymkiewicz G, Jaskiewicz P and Kowalski DM: Two neoplasms rich in small lymphocytes, B1B2 thymoma and small lymphocytic lymphoma, intermingled in one tumor mass. A case report. Pol J Pathol 68: 75-81, 2017.

78. Rose BS, Jeong JH, Nath SK, Lu SM and Mell LK: Population-based study of competing mortality in head and neck cancer. J Clin Oncol 29: 3503-3509, 2011.

79. Yamashita T, Araki K, Tomifuji M, Tanaka Y, Harada E, Suzuki T, Miyamoto S and Shiotani A: Clinical features and treatment outcomes of Japanese head and neck cancer patients with a second primary cancer. Asia Pac J Clin Oncol 13: 172-178, 2017.

80. Bunbanjerdsuk S, Vorasan N, Saethang T, Pongrujikorn T, Pangpunyakulchai D, Mongkonsiri N, Arsa L, Thokanit N, Pongsapich W, Anekpuritanang T, et al: Oncoproteomic and gene expression analyses identify prognostic biomarkers for second primary malignancy in patients with head and neck squamous cell carcinoma. Mod Pathol: Feb 8, 2019 (Epub ahead of print). doi: 10.1038/s41379-019-0211-2.

81. da Silva SD, Morand GB, Alobaid FA, Hier MP, Mlynarek AM, Alaoui-Jamali MA and Kowalski LP: Epithelial-mesenchymal transition (EMT) markers have prognostic impact in multiple primary oral squamous cell carcinoma. Clin Exp Metastasis 32: 55-63, 2015.

82. Sun Y, Yu W, Sturgis EM, Peng W, Lei D, Wei Q, Song X and $\mathrm{Li}$ G: Site disparities in apoptotic variants as predictors of risk for second primary malignancy in patients with squamous cell carcinoma of the head and neck. BMC Cancer 16: 70, 2016.

83. Zhou S, Lu Z, Wu H, Gu CY, Zhang DY, Sun WL, Ma X and Liu HC: Synchronous multiple primary gallbladder and gastric malignancies: Report of two cases and review of the literature. Mol Clin Oncol 7: 869-873, 2017.

84. Guy GP Jr, Yabroff KR, Ekwueme DU, Smith AW, Dowling EC, Rechis R, Nutt S and Richardson LC: Estimating the health and economic burden of cancer among those diagnosed as adolescents and young adults. Health Aff (Millwood) 33: 1024-1031, 2014.

85. Choi J, Lee M, Ki M, Lee JY, Song YJ, Kim M, Lee S, Park S and Lim J: Risk factors for feelings of sadness and suicide attempts among cancer survivors in South Korea: Findings from nationwide cross-sectional study (KNHANES IV-VI). BMJ Open 7: e016130, 2017.

This work is licensed under a Creative Commons Attribution-NonCommercial-NoDerivatives 4.0 International (CC BY-NC-ND 4.0) License. 